ciency virus infection: recommendations of the Advisory Committee for the Elimination of Tuberculosis (ACET). MMWR 1989;38:236-50

12 Medical Research Council Tuberculosis and Chest Diseases Unit. National survey of notifications of tuberculosis in England and Wales in 1983. Br Med $\mathcal{F}$ 1985;291:658-61.

13 Watson J, Gill ON. Tuberculosis and HIV infection: surveillance in England and Wales [Abstract]. Thorax 1988; $43: 855 \mathrm{P}$

14 Reichman LB, Felton CB, Edsall JR. Drug dependence, a possible new risk factor for tuberculosis disease. Arch Intern Med 1979;139:337-9.

15 Braun MM, Truman BI, Maguire B, et al. Increasing incidence of tuberculosis in a prison inmate population. Association with HIV infection. FAMA 1989:261:393-7.

population. Association with HIV infection. FAMA 1989;261:393-7.
Darbyshire JH. Tuberculosis in prisons. Br Med F 1989;299:874-5.

17 Doble N, Hykin P, Shaw R, Keal EE. Pulmonary Mycobacterium tuberculosis in acquired immune deficiency syndrome. Br Med F 1985;291:849-50.

immune deficiency syndrome. Br Med $\mathcal{~}$ 1985;291:849-50.
Goldman KP. AIDS and tuberculosis. Br Med F 1987;295:511-2.

18 Goldman KP. AIDS and tuberculosis. Br Med f 1987;295:511-2. Helbert M, Robinson D, Buchanan D, et al. Mycobacterial infection in patients infected with the human immunodeficiency virus. Thorax (in press).

20 Sunderam G, McDonald RJ, Maniatis T, Oleske J, Kapila R, Reichman LB. Tuberculosis as a manifestation of the acquired immunodeficiency syndrome (AIDS). FAMA 1986;256:362-6.

21 Chaisson RE, Schecter GF, Theuer CP, Rutherford GW, Echenberg DF, Hopewell PC Tuberculosis in patients with the acquired immunodeficiency syndrome. Clinical features, response to therapy and survival. Am Rev Respir Dis 1987;136:570-4.

22 British Thoracic Society. Control and prevention of tuberculosis: a code of practice. Br Med $\mathcal{F}$ 1983;287:1118-21.

23 Centers for Disease Control. Mycobacterium tuberculosis transmission in a health clinic-Florida, 1988. MMWR 1989;38:256-64.

24 Adler MW ABC of AIDS. Development of the epidemic. Br Med f 1987:294:1083-5.

25 Miller D. ABC of AIDS. Counselling. Br Med f 1987;294:1671-4.

26 Centers for Disease Control. Disseminated Mycobacterium bovis infection from BCG vaccination of a patient with acquired immunodeficiency syndrome. MMWR 1985;34:227-8.

27 Joint Committee on Vaccination and Immunisation. Immunisation against infectious disease. London: HMSO, 1988.

\section{Medical audit}

\section{Closing the feedback loop is vital}

Good clinicians have always organised some kind of systematic review of their daily work, recording and assessing the accuracy of their diagnosis and the outcome of their treatment. We have learnt to call this kind of activity audit.

Everyone now has to become an auditor; the NHS Bill requires general practitioners and hospital staff to engage in regular audit by 1991, the royal colleges and faculties require evidence of audit before accrediting posts for specialist training, and hospital managers seem to believe that audit will be the key to achieving their prime challenge - a high quality service at the lowest possible cost.

A lot of thinking, talking, and writing about audit is still, however, ill focused and vague. The word audit is not some sort of magic talisman that will change practice simply by its repetition. There are some basic principles, now generally agreed. ${ }^{1}$ This week ( $\mathrm{p} 85$ ) the $B M \mathcal{F}$ begins publication of a new regular series, Audit in Practice, which will, we hope, help readers to understand those principles and see how other groups of clinicians have been achieving audit. The section will include some submitted articles accepted after the normal editorial process of assessment and peer review; but there will also be commissioned articles explaining practical aspects of audit and a news and diary section prepared by the King's Fund Centre.

In deciding whether or not to publish an article describing medical audit in a hospital or general practice setting we shall look for specific features. As with any research study we shall need clear statements of why the project was started, what was done, what was found, and how the data were analysed. But the essence of audit is that it should be designed to achieve change. This is true whether the audit is of process (examining records and other data to find out how patients are being treated) or of outcome (looking at the results of treatment). The first stage in the audit is defining the standard that should be achieved (the proportion of children vaccinated or of adults having their blood pressure recorded, for example) or the pattern of investigation and treatment to be followed for patients with a defined condition (such as haematemesis and melaena in a patient with no previous episodes of bleeding).
Next, the auditing group assesses how their performance has been measuring up to the agreed standard and the circumstances of any omissions or oversights.

From that assessment should come practical conclusionshow performance can be brought closer to the agreed standard or how the standard can be modified to improve outcome further. Next - and this is the crucial step so often omitted in reports submitted for publication - the conclusions should be agreed with the clinicians and put into practice. Finally, the audit must be repeated to ensure that change has occurred in the right direction. Without this "closing of the feedback loop" audit may be little more than a pious exercise in self congratulation.

Where do the standards come from? Sometimes they will be consensus statements, sometimes guidelines agreed by expert bodies such as colleges and faculties. In many cases the primary source will be the conclusions of formal prospective clinical trials. Sometimes a group of clinicians may find that the audit they had in mind cannot be started because there is no agreed protocol of management and their first task may then be to set up an appropriate trial. And what should be the priority topics for clinical audit? Here each group of doctors will make its own decisions, but data collected by community physicians will often provide a basis for identifying targets in terms of patients to be screened or treated, mortality and morbidity, and so on.

All concerned have a lot to learn-and that includes the editorial team responsible for the new section. The format of audit articles seems likely to evolve, but at this stage we believe that most such articles should have a structured abstract setting out the purpose and design of the study, the conclusions reached, the action taken, and-ideally-the results of that action. The catchment population or number of participating hospitals or centres should also be given. Statements for revision of regional or district guidelines generally have less impact than recommendations to specified regional or national bodies. In addition, the first of this series includes a review of a clinical audit kit, and we shall be pleased to consider other similar material for future review in the section.

The whole process should be exciting and stimulating, and standards of care should improve simply by the process of being examined and questioned. Of course most clinical audits will not warrant publication as they will repeat work already done and reported elsewhere; but we should like to hear about any experiences - successes or failures - that may have practical lessons for others.

Deputy editor, $B M \mathcal{F}$

TONY SMITH

1 Shaw CD, Costain DW. Guidelines for medical audit: seven principles. Br Med $\mathcal{f}$ 1989;299:498-9.

\section{Britain bans oral snuff}

\section{Government's action is tough and commendable}

Just before Christmas the Department of Health announced a ban on oral snuff to come into effect in March 1990, under consumer protection legislation. The move will prohibit the supply of oral snuff (the best known brand is Skoal Bandits) and will mean the closure of the factory in Scotland originally built with the aid of a government grant. In announcing the ban the Secretary of State for Health, Kenneth Clarke, 